\title{
Analysis and investigation of the third drainage ditch pollution situation in Ningxia based on multivariate statistics
}

\author{
Linfeng $\operatorname{Tian}^{1,2^{*}}$ \\ ${ }^{1}$ School of Environmental Science and Engineering, Tong ji University, Shanghai, 200092, PR China \\ ${ }^{2}$ Environmental monitoring station, Shizuishan 753000, PR China
}

\begin{abstract}
This article takes the third drainage ditch in Ningxia as the research object, and uses the multivariate statistics method to analyze the interrelationship between the four major pollutants at nine regional points in the main pollution ditch section of the third drainage ditch throughout the year from the perspective of time and space, to improve the water environment quality. SPSS (Social Statistics Software Package) is used to analyze chemical oxygen demand, total phosphorus, total nitrogen, ammonia nitrogen, and index of major pollutants of permanganate. The research results show that the main pollutants and the degree of pollution affecting the water quality of the third drainage ditch are: total nitrogen $>$ ammonia nitrogen $>$ total phosphorus $>$ chemical oxygen demand. At the end of San'er, ammonia nitrogen and total nitrogen were the most polluted. At the Dawukou section of San'er, the chemical oxygen demand and total phosphorus were the heaviest.
\end{abstract}

\section{Introduction}

Water and energy are the most important resources for the national economic development, and the basis for the harmonious development of society, ecology and economy[1-3]. The main feature of water utilization in Ningxia is that the northern Yellow River irrigation area is mainly based on the Yellow River water. And the central arid area is dominated by the Yellow River. The southern loess hilly area is mainly based on the development and utilization of local water. Finally, irrigation drainage enters the Yellow River through various ditchs with the agricultural drainage form[4,5]. Agricultural drainage carries a large amount of pollutants, such as fertilizers and pesticides that are washed out from farmland soil, which is an important part of agricultural non-point source pollution[6-9]. The agricultural drainage process are uncertainty in time and dispersion in space, therefore, the control and treatment of agricultural pollution have always been a worldwide problem[10-13]. The Yellow River irrigation area is located in the northwest inland. The area is dry with less rain and strong evaporation. The Yellow River transit water is the most important source to use[14-16]. Meanwhile, due to high groundwater level, serious salinization in soil, and backward agricultural production, the area has been dominated by flood irrigation for many years. In order to drain in time, the drainage system is developed, farmland drainage and the industrial and productive domestic sewage along the way finally enters the Yellow River through the drainage ditch[17-20]. The third drainage ditch is the longest drainage system in
Ningxia. The main function is first to undertake the drainage task including Jinfeng zone, Helan County, Pingluo County, Huinong zone and State Farm with 1.45 million mu farmland. Which is the longest pitch with the largest drainage area in the northern YinChuan irrigation area. Second, it undertakes the task of flood discharge in the east of Helan Mountain. The third is to undertake some domestic sewage and industrial wastewater in the drainage area[21,22].

The paper takes the third drainage ditch as the research object, and uses the multivariate statistics principle to study the relationship and distribution characteristics among the four main pollutants in the 9 points of the main pollution ditch along the third drainage ditch from the time dimension and spatial dimension. Then explore the main pollution causes of the third drainage ditch, determine the drainage ditch pollution control unit, to provide reference for the improvement of water quality and pollution prevention of the third drainage ditch, and provide technical methods for other drainage ditch research in the northwest region.

\section{Experimental section}

\subsection{Study area}

The third drainage ditch starts in Jinfeng District, Yinchuan City. The head of the ditch collects the agricultural drainage from Fengqinggou section, the Hongqigou section, the Shengligou, Xiaodonggou, Tuanjiegou, and Siqinggou, etc. Crossing Helan County,

\footnotetext{
*Corresponding author: tianlinfeng448@126.com
} 
Pingluo County and Huinong District of Shizuishan City, and entering the Yellow River at the Yellow River Bridge in Huinong District, Shizuishan City. The total length of the ditch is $90.38 \mathrm{~km}$, the catchment area is $5372.43 \mathrm{~km}^{2}$, the runoff is $10.3-120 \mathrm{~m}^{3} / \mathrm{s}$, the average annual flow is $5.1 \mathrm{~m}^{3} / \mathrm{s}$, and the annual runoff is about 160 million $\mathrm{m}^{3}$. San'er branch gully is the largest gully of the third drainage ditch. It merges into the third drainage ditch in Pingluo County, the total length is about $40 \mathrm{~km}$, the average annual flow is $2.1 \mathrm{~m}^{3} / \mathrm{s}$, and the annual runoff is about 0.5 billion $\mathrm{m}^{3}$. The study area is a semiarid desert area with a temperate continental climate.

\subsection{Sample collection and analysis}

According to the third drainage flow area, sewage outlets distribution and aquatic plants distribution, we have set 9 sampling points covering the entire water of the drainage ditch. The sampling time is the whole of 2018. It monitors once a month. The water sample is collected at $0.5 \mathrm{~m}$ below the water surface at each time, and each point is collected 3 times. The sample is evenly mixed half an hour and pipetted with water or water several times. Then, add the appropriate fixative and bring it back to the laboratory for analysis. The collected samples are strictly monitored in accordance with the Surface Water Environmental Quality Standard (GB 3838-2002). The $\mathrm{NH}_{4}{ }^{+}-\mathrm{N}, \mathrm{TN}, \mathrm{COD}, \mathrm{TP}$ is determined respectively by Nessler's Reagents spectrophotometer, potassium persulfate oxygen ultraviolet spectrophotometry, potassium dichromate oxidation method, ammonium molybdate spectrophotometry. The test results are evaluated with single factor water quality according to the Class III standard limits of the Surface Water Environmental Quality Standards (GB3838-2002).

\subsection{Multivariate statistical analysis}

The pollution analysis of water environmental areas was conducted from the perspective of statistics, which can reveal the main contaminant sources of water such as lakes and rivers as well as the trends of various pollution in a more scientifically manner [23-26]. At present, the statistics package for social sciences (SPSS) is a common research method for environmental research in recent years, which primarily uses data-based data mapping to convert the abstract numbers into graphics that are easy to understand and analyze [27-29], in which correlation analysis is used to analyze signs associate with each other in the whole, that is, a analysis of signs with causal relationships in the whole. Correlation analysis is a process that describes the strength of a relationship between objective things and demonstrates it with appropriate statistical indicators.

\section{Results and discussion}

\subsection{Annual variation of water quality in the third drainage ditch}

The end of the third drainage ditch has been monitored since 2012. From the monitoring results of many years, according to the standard limit value of surface water class IV, the main pollutants are $\mathrm{NH}_{4}{ }^{+}-\mathrm{N}, \mathrm{COD}$, TP and $\mathrm{TN}$, and it has always been heavy polluted water bodies which quality inferior to Class $\mathrm{V}$ (Table 1). The monitoring results show that the $\mathrm{NH}_{4}{ }^{+}-\mathrm{N}$ concentration range is $7.4-25.4 \mathrm{mg} / \mathrm{L}$, the maximum exceeds 16 times. The COD concentration range is $56.7-126 \mathrm{mg} / \mathrm{L}$. The maximum exceeds 3.3 times. The TP concentration range is $0.45-1.27 \mathrm{mg} / \mathrm{L}$, the maximum exceeds 3.2 times. The $\mathrm{TN}$ concentration range is $17.7-28.2 \mathrm{mg} / \mathrm{L}$, the maximum exceeds 17 times.

Table 1. Annual Comparison of Main Monitoring Items in Shahu from 2012 to 2018

\begin{tabular}{ccccccc}
\hline Annual & $\mathrm{pH}$ & $\mathrm{NH}_{3}-\mathrm{N}$ & $\mathrm{COD}$ & $\mathrm{TP}$ & $\mathrm{TN}$ & Category \\
\hline 2012 & 8.2 & 13.5 & 87 & 0.45 & 17.9 & exceed V \\
2013 & 8.5 & 15.6 & 126 & 0.96 & 21.2 & exceed V \\
2014 & 8.2 & 19.7 & 97 & 1.27 & $/$ & exceed V \\
2015 & 8.4 & 7.4 & 103 & 0.50 & $/$ & exceed V \\
2016 & $7.97-8.68$ & 11.0 & 85.8 & 0.59 & $/$ & exceed V \\
2017 & $7.74-8.47$ & 13.7 & 62.1 & 0.60 & 17.7 & exceed V \\
2018 & $7.57-8.60$ & 25.4 & 56.7 & 0.74 & 28.2 & exceed V \\
Mean & $7.57-8.68$ & 15.2 & 88.2 & 0.73 & 21.3 & - \\
Standard & $6-9$ & 1.5 & 30 & 0.3 & 1.5 & IV \\
Limits & & & & & &
\end{tabular}

\subsection{Main monitoring section of the third drainage ditch}

From the monitoring results in recent years, the main pollutants and pollution degree which affected the water quality of the third drainage ditch were: $\mathrm{TN}>\mathrm{NH}_{4}{ }^{+-}$ $\mathrm{N}>\mathrm{TP}>\mathrm{COD}$. The main pollutant monitoring concentration ranges of 9 monitoring points in this survey (Table 1). Using $\mathrm{NH}_{4}^{+}-\mathrm{N}$ as the reference pollutant for analysis, pollution degree of each monitoring section was: Site- $6>$ Site- $8>$ Site- $4>$ Site$7>$ Site- $9>$ Site- $3>$ Site- $2>$ Site- $1>$ Site- 5 . Using COD as the reference pollutant for analysis, pollution degree of each monitoring section was: Site- $6>$ Site- $3>$ Site- $8>$ Site$4>$ Site-7 $>$ Site-5 $>$ Site- $2>$ Site- $9>$ Site- 1 . Using TP as the 
reference pollutant for analysis, pollution degree of each monitoring section was:Site-3 $>$ Site- $4>$ Site- $8>$ Site$7>$ Site- $6>$ Site- $9>$ Site- $1>$ Site- $2>$ Site- 5 . Using TN as the reference pollutant for analysis, pollution degree of each monitoring section was: Site-6 $>$ Site- $8>$ Site- $4>$ Site$7>$ Site- $9>$ Site- $1>$ Site- $3>$ Site- $2>$ Site -5 . From the monitoring section contaminant trend chart (Fig 1), it shows that the contaminated segment of san'er branch gully was centered on the Dawukou section of Site- 3 that the concentration of contaminants of inbound section of san'er branch gully were generally elevated when flowing across the Site-3 section, which caused deterioration of water quality flowing into the third drainage ditch from san'er branch gully. The research result shows that Dawukou section of san'er branch gully may exist a large pollution source. When entering the territory of Shizui Mountain the water quality from the third drainage ditch was better as a whole. But after flowing through the Pingluo section, the concentration of contaminants has significantly raised up, and the maximum monitoring concentration appeared in the Site6 section. After flowing across Site- 8 and Site-9, the concentration of contaminants was naturally dropped. The research results shows that the Pingluo section of the third drainage ditch may exist a large pollution source.

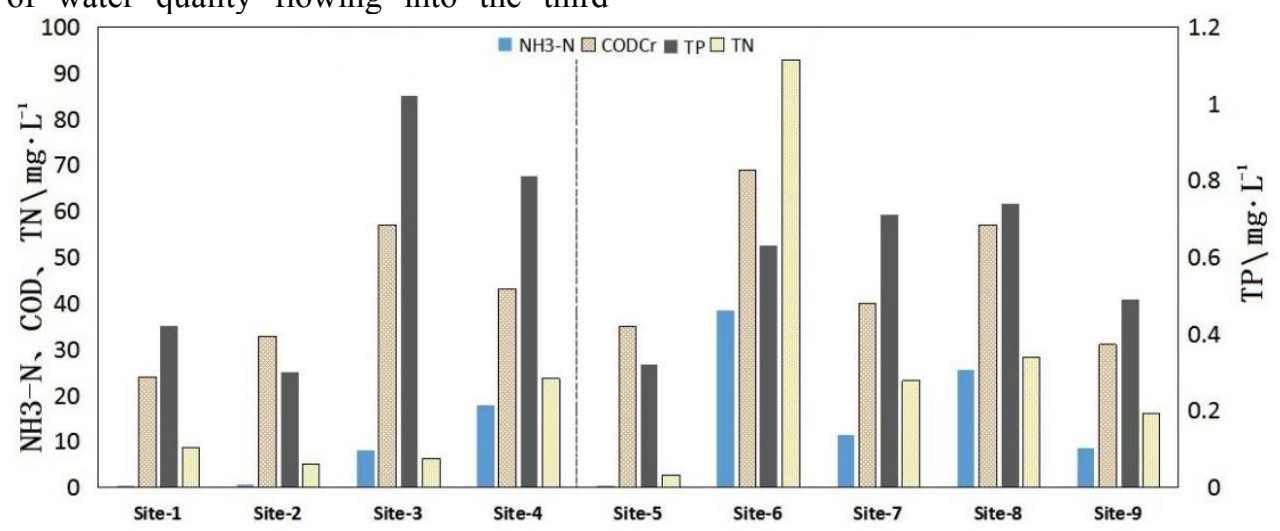

Fig 1. Variation of main pollutant concentration in each monitoring section of the third drainage ditch

From nine investigation points a total of 108 monitoring data sets were obtained (Table 2). For san'er branch gully area, the $\mathrm{NH}_{4}{ }^{+}-\mathrm{N}$ pollution mainly occurred in Site-4, with an over-limit rate of $58.3 \%$ in the monitoring section; the COD pollution primarily occurred in Site-3, with a section over-limit rate of $66.7 \%$; the TP pollution mainly occurred in Site-3, with a section over-limit rate of $58.3 \%$; and the TN pollution mostly occurred in Site-4, with a section over-limit rate of $100 \%$. For the third drainage ditch area, the $\mathrm{NH}_{4}{ }^{+}-\mathrm{N}$ pollution primarily occurred in the territory of Shuizui Mountain (Site-6, Site-7, Site-8), which has been out of limits throughout the year; the COD pollution mainly occurred in Site-6, with an over-limit rate of $85.7 \%$; the TP pollution primarily occurred in Site- 6 , with an overlimit rate of $71.4 \%$; and the TN pollution appeared across the whole basin that the over-limit rate of $\mathrm{TN}$ in five monitoring sections of the third drainage ditch was $100 \%$.

Table 2. Summary of major pollutants at different monitoring locations in different seasons $(\mathrm{mg} \cdot \mathrm{L}-1)$

\begin{tabular}{|c|c|c|c|c|c|c|}
\hline Sampling & Points & $\mathrm{pH}$ & $\mathrm{NH}_{3}-\mathrm{N}$ & COD & $\mathrm{TP}$ & $\mathrm{TN}$ \\
\hline \multirow{3}{*}{$\begin{array}{l}\text { Inbound of san'er branch } \\
\text { gully (Site-1) }\end{array}$} & $\begin{array}{l}\text { Concentration range } \\
\text { ra }\end{array}$ & $7.67-8.34$ & $0.144-2.02$ & $14-37$ & $0.11-1.58$ & $1.79-28.4$ \\
\hline & Mean & / & 0.469 & 24 & 0.42 & 8.66 \\
\hline & Standard deviation & 0.25 & 0.52 & 6.45 & 0.41 & 9.74 \\
\hline \multirow{5}{*}{$\begin{array}{l}\text { Pingluo section of san'er } \\
\text { branch gully } \\
\text { ( Site- } 2)\end{array}$} & Over-limit rate & 0 & $8.3 \%$ & $16.7 \%$ & $50 \%$ & $100 \%$ \\
\hline & Concentration range & $7.49-8.78$ & $0.071-2.50$ & $18-75$ & $0.08-0.67$ & $0.75-15.0$ \\
\hline & Mean & l & 0.72 & 32.9 & 0.30 & 5.14 \\
\hline & Standard deviation & 0.33 & 0.82 & 14.7 & 0.20 & 6.62 \\
\hline & over-limit rate & 0 & $16.7 \%$ & $41.7 \%$ & $33.3 \%$ & $75 \%$ \\
\hline \multirow{3}{*}{$\begin{array}{l}\text { Dawukou section of } \\
\text { San'er branch gully } \\
\text { (Site-3) }\end{array}$} & Concentration range & $7.80-8.89$ & $0.071-39.1$ & $18-142$ & $0.05-4.43$ & $1.32-18.1$ \\
\hline & Mean & / & 7.98 & 57 & 1.02 & 6.35 \\
\hline & Standard deviation & 0.36 & 13.8 & 40.1 & 1.41 & 7.89 \\
\hline
\end{tabular}




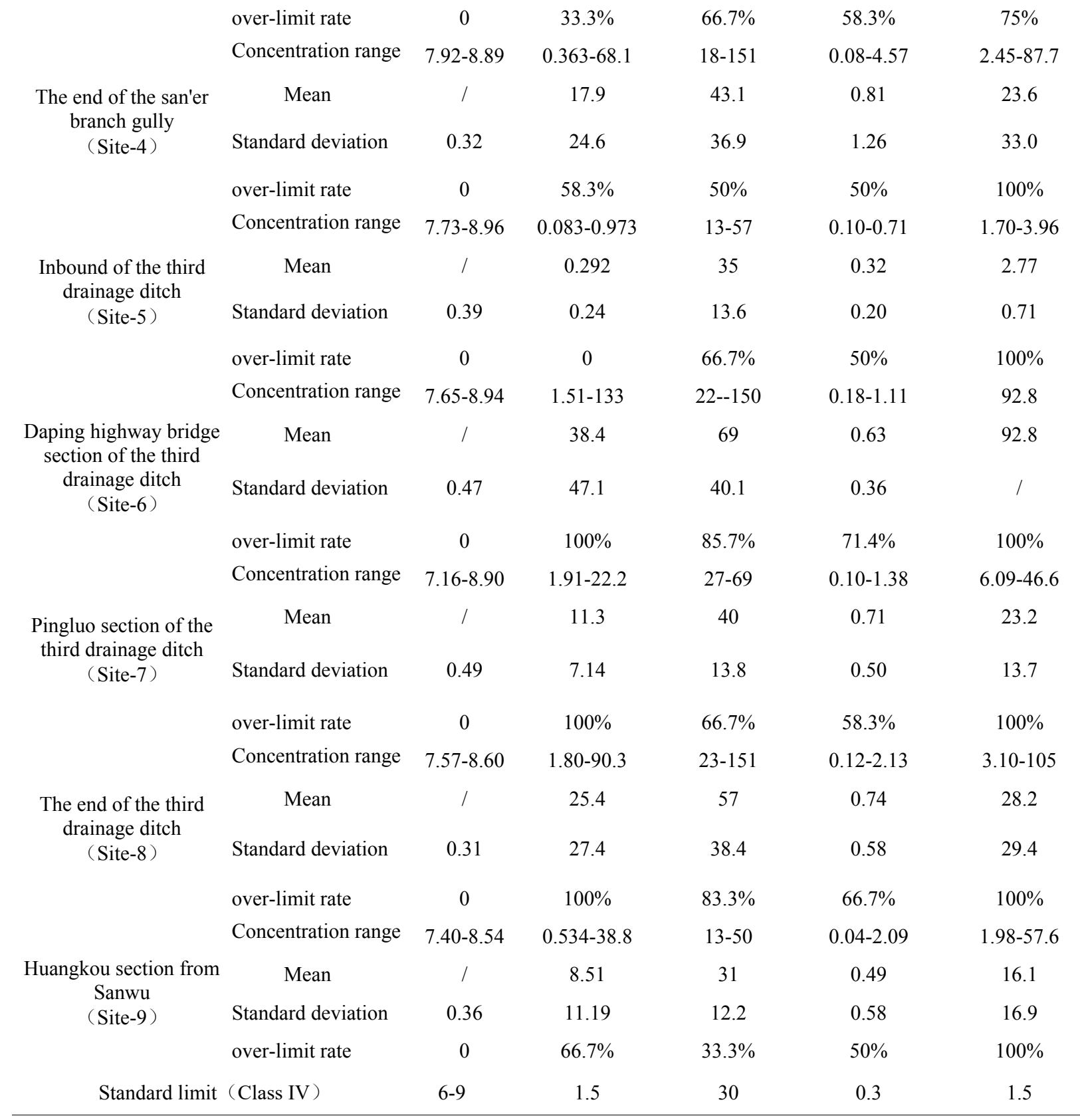

demonstrating that the concentration of $\mathrm{NH}_{4}^{+}-\mathrm{N}$ of

\subsection{Correlation analysis}

The paper takes $\mathrm{NH}_{4}{ }^{+}-\mathrm{N}, \mathrm{COD}, \mathrm{TP}, \mathrm{TN}$ relatively as the reference pollutants for the analysis. Using the correlation of binary distance variables to analyze the correlation between each monitoring point(Table 3,Table 4) ,demonstrating that the correlation characteristics between main pollutants in each monitoring section. The analysis results show that the 9 monitoring points have different correlations for different pollutants.

Using the $\mathrm{NH}_{4}{ }^{+}-\mathrm{N}$ as the reference pollutant for analysis. Site- 1 and Site-3 show a significant positive correlation $(\mathrm{r} 1-3=0.839, \mathrm{P}<0.01)$, verifying that the concentration of $\mathrm{NH}_{4}{ }^{+}-\mathrm{N}$ of Dawukou section in San'er branch gully would rise as the inbound concentration of San'er branch gully increased. Site- 2 and Site- 8 show a significant positive correlation $(\mathrm{r} 2-8=0.810, \mathrm{P}<0.01)$,
Huinong section in the third drainage ditch would elevate as the concentration of Pingluo section in San'er branch gully ramped. Site-4 and Site-7, Site-8, Site-9 are positive correlated, showing that the concentration of $\mathrm{NH}_{4}{ }^{+}-\mathrm{N}$ at the end of San'er branch gully would lead to the augmentation of the concentration at the confluence of Pingluo section of the third drainage ditch, Huinong section of the third drainage ditch and the third and the fifth drainage ditchs at the entrance into the Yellow River in a certain extent.

Using the COD as the reference pollutant for analysis. Site- 1 and Site- 4 show a significant positive correlation ( $\mathrm{r} 1-9=0.778, \mathrm{P}<0.01)$, demonstrating that the increase of COD concentration at the end of the third drainage ditch caused by the San'er branch gully entry section. Site- 4 and Site- 8 show a certain positive correlation ( r4$8=0.696, \mathrm{P}<0.05)$, verifying that the concentration of COD at the end of the third drainage ditch would elevate as the concentration at the end of the San'er branch gully 
ramped. Site-6 and Site-7 show a certain positive correlation $(\mathrm{r} 6-7=0.852, \mathrm{P}<0.05)$, showing that the concentration of COD of Pingluo section in the third drainage ditch would elevate as the monitoring concentration of Pingluo section in the third drainage ditch ramped.

Using the TP as the reference pollutant for analysis. Site- 1 and Site-9 show a significant positive correlation ( $11-9=0.778, \mathrm{P}<0.01)$ demonstrating that the concentration of TP of Huangkou section from Sanwu would increase as the concentration of San'er branch gully entry section rose. Site- 2 and Site- 8 are positive correlated ( $\mathrm{r} 2-8=0.741, \mathrm{P}<0.01)$, verifying that the concentration of TP at the end of the third drainage ditch would elevate as the concentration of Pingluo section in San'er branch gully ramped. Site-7 and Site- 8 are positive correlated $(\mathrm{r} 7-8=0.819, \mathrm{P}<0.01)$, showing that the concentration of TP of Huinong section in the third drainage ditch would elevate as the concentration of Pingluo section in San'er branch gully ramped.

Using the TN as the reference pollutant for analysis. Site- 2 and Site-3 show a significant positive correlation ( $\mathrm{r} 2-3=0.991, \mathrm{P}<0.01$ ), demonstrating that the concentration of TN of Dawukou section in San'er branch gully would increase as the concentration of Pingluo section in San'er branch gully rose. Site-4 and Site-1, Site-2, Site-3, Site-8, Site-9 are positive correlated $\quad(\mathrm{r} 1-4=0.813, \mathrm{r} 2-4=0.999, \mathrm{r} 3-4=0.993, \mathrm{r} 4-$ $8=0.773, \mathrm{r} 4-9=0.942, \mathrm{P}<0.01)$, verifying that the concentration of TN at the end of San'er branch gully would elevate as each monitoring section of San'er branch gully ramped, and the concentration of TN at the Huangkou section from Sanwu and the end of the third drainage ditch would rise as the concentration at the end of San'er branch gully increased.

Table 3. Correlation analysis of monitoring indexes between April and June in Shahu Lake

\begin{tabular}{llllllllll} 
& Site-1 & Site-2 & Site-3 & Site-4 & Site-5 & Site-6 & Site-7 & Site-8 & Site-9 \\
\cline { 2 - 8 } Site-1 & 1 & 0.075 & 0.166 & $0.814^{* *}$ & 0.157 & -0.162 & 0.082 & 0.531 & 0.409 \\
Site-2 & 0.351 & 1 & 0.124 & 0.003 & -0.065 & 0.140 & 0.033 & 0.070 & 0.442 \\
Site-3 & $0.839^{* *}$ & 0.399 & 1 & 0.010 & -0.068 & -0.005 & -0.021 & 0.349 & 0.486 \\
Site-4 & 0.286 & 0.513 & 0.485 & 1 & -0.081 & 0.042 & -0.053 & $0.696^{*}$ & 0.475 \\
Site-5 & 0.201 & -0.069 & 0.006 & -0.225 & 1 & 0.704 & 0.495 & -0.552 & -0.183 \\
Site-6 & -0.326 & -0.192 & -0.166 & -0.126 & -0.277 & 1 & $0.852^{*}$ & 0.491 & 0.217 \\
Site-7 & 0.256 & $0.581^{*}$ & 0.425 & $0.606^{*}$ & -0.163 & 0.664 & 1 & -0.143 & 0.084 \\
Site-8 & 0.563 & $0.810^{* *}$ & 0.568 & $0.703^{*}$ & 0.115 & 0.477 & $0.717^{* *}$ & 1 & 0.461 \\
Site-9 & 0.074 & $0.665^{*}$ & 0.507 & $0.647^{*}$ & -0.189 & -0.144 & $0.604^{*}$ & $0.581^{*}$ & 1 \\
\hline
\end{tabular}

Note: $* *$ indicates that the relevant significant level is 0.01 (two-tailed), * indicates that the relevant significant level is 0.05 (two-tailed). The blank area is based on ammonia $\mathrm{NH}_{3}-\mathrm{N}$ and the gray area is based on COD.

Table 4. Correlation analysis of monitoring indexes between August and October in Shahu Lake

\begin{tabular}{rrrrrrrrrr}
\hline & Site-1 & \multicolumn{1}{c}{ Site-2 } & Site-3 & Site-4 & Site-5 & Site-6 & Site-7 & Site-8 & Site-9 \\
\hline Site-1 & 1 & 0.925 & 0.925 & $0.813^{* *}$ & -0.221 & - & 0.298 & 0.435 & $0.606^{*}$ \\
Site-2 & 0.135 & 1 & $0.991^{* *}$ & $0.999^{* *}$ & -0.336 & - & 0.421 & $0.986^{*}$ & $0.953^{*}$ \\
Site-3 & 0.451 & 0.250 & 1 & $0.993^{* *}$ & -0.411 & - & 0.300 & $0.956^{*}$ & $0.972^{*}$ \\
Site-4 & 0.191 & 0.294 & 0.137 & 1 & -0.489 & - & 0.512 & $0.773^{* *}$ & $0.942^{* *}$ \\
Site-5 & 0.094 & 0.443 & -0.397 & -0.061 & 1 & - & 0.035 & -0.163 & -0.173 \\
Site-6 & 0.473 & 0.651 & $0.776^{*}$ & 0.734 & $0.760^{*}$ & 1 & - & -1 & - \\
Site-7 & 0.445 & 0.539 & $0.641^{*}$ & $0.633^{*}$ & -0.021 & $0.839^{*}$ & & 0.637 & 0.468 \\
Site-8 & 0.191 & $0.741^{* *}$ & $0.585^{*}$ & 0.346 & 0.047 & $0.815^{*}$ & $0.819^{* *}$ & 1 & $0.727^{*}$ \\
Site-9 & $0.778^{* *}$ & 0.272 & 0.368 & 0.486 & 0.017 & $0.791^{*}$ & $0.658^{*}$ & 0.533 & 1 \\
\hline
\end{tabular}

Note: $* *$ indicates that the relevant significant level is 0.01 (two-tailed), $*$ indicates that the relevant significant level is 0.05 (two-tailed). The blank area is based on ammonia TP and the gray area is based on TN. 


\subsection{Pollution control unit analysis}

The delineation of pollution control unit is for starting Comprehensive improvement of water environment in unit more accurately to carry out the project periodic. According to the spatial differences in environmental functions and the refinement of various main body functional areas, a natural boundary is formed, combined with the division of the administrative boundary, the natural ecological red line and other environmental division control units are determined. It can be divided into three pollution control areas. The first is the upstream water pollutant control area. The division is mainly based on the higher concentration of pollutants in the upstream area, and there are fewer sewage outlets connect the third drainage ditch and San'er branch gully. The area needs to strengthen pollution monitoring and management. The second is the midstream pollution comprehensive control zone. The division is mainly based on the fact that there are many sewage outlets, the wastewater discharge is larger, and the pollution concentration of each section is heavier. The monitoring concentration is highly volatile, and the area should strengthen the supervision and management of the discharge outlets. The third is the downstream pollution reduction and ecological restoration control area. There is no wastewater discharge port, and the river section is long, which is convenient for the reduction of water pollutants. The area is suitable for the natural degradation of pollutants by constructing ecological wetlands.

\section{Conclusions}

From nine investigation points, a total of 108 monitoring data of this survey indicated that the $\mathrm{NH}_{4}{ }^{+}-\mathrm{N}$ and $\mathrm{TN}$ pollution were the heaviest at the end of the San'er branch gully which the over-limit rates were $58.3 \%$ and $100 \%$ respectively. The COD and TP pollution were the heaviest at Dawukou section in San'er branch gully which the over-limit rates were $66.7 \%$ and $58.3 \%$ respectively. For San'er branch gully area, the section of Daping highway bridge section in the third drainage ditch with the heaviest pollution, the over-limit rates of $\mathrm{NH}_{4}{ }^{+}-\mathrm{N}, \mathrm{COD}, \mathrm{TP}, \mathrm{TN}$ were $100 \%, 85.7 \%, 71.4 \%$ and $100 \%$. The rate of $\mathrm{NH}_{4}{ }^{+}-\mathrm{N}$ were $100 \%$ at the Pingluo section and the end of the third drainage ditch. The TN over-limit rate of the five monitoring sections were $100 \%$ in the whole basin of the third drainage ditch.

The 9 monitoring points showed the correlations with different degrees, and the pollutants in each monitoring section were related closely. Using the $\mathrm{NH}_{4}{ }^{+}-\mathrm{N}$ as the reference pollutant for analysis, the correlations among the monitoring points reached $\mathrm{r} 1-3=0.839(\mathrm{P}<0.01)$, $\mathrm{r} 2-$ $8=0.810(\mathrm{P}<0.01)$ respectively, Site- 4 and Site-7, Site- 8 , Site-9 all showed a certain positive correlation. Using the $\mathrm{COD}$ as the reference pollutant for analysis, the correlate ons among the monitoring points reached $\mathrm{rl}$ $4=0.814(\mathrm{P}<0.01), \quad \mathrm{r} 4-8=0.696(\mathrm{P}<0.05), \quad \mathrm{r} 6-$ $7=0.852(\mathrm{P}<0.05)$ respectively. Using the $\mathrm{TP}$ as the reference pollutant for analysis, the correlations among the monitoring points reached $\mathrm{r} 1-9=0.778(\mathrm{P}<0.01)$, r2$8=0.741(\mathrm{P}<0.01), \mathrm{r} 7-8=0.819(\mathrm{P}<0.01)$. Using the $\mathrm{TN}$ as the reference pollutant for analysis, the correlations among the monitoring points reached r2-3 $=0.991$, r1$4=0.813, \quad \mathrm{r} 2-4=0.999, \quad \mathrm{r} 3-4=0.993, \quad \mathrm{r} 4-8=0.773, \quad \mathrm{r} 4-$ $9=0.942(\mathrm{P}<0.01)$.

The paper uses a variety of comprehensive analysis methods (geostatistical analysis, correlation analysis). According to the distribution characteristics of various points, and pollutants, the third drainage ditch is divided into three areas: the upstream water pollutant control area, the middle pollution comprehensive control area, the downstream pollution reduction and the ecological restoration control area. Specific measures such as regional planning, watershed management, and upstream management and control are expected to further improve the current status of water environment quality in the third drainage ditch.

\section{References}

1. Boulay, A. M., Bulle, C., Bayart, J. B., Deschênes, L., Margni, M. (2011) Regional characterization of freshwater use in LCA: modeling direct impacts on human health. Environ. Sci. Technol. 45, 8948-8957.

2. Boreen, A.L., Arnold,W.A., McNeill, K. (2004) Photochemical fate of sulfa drugs in the aquatic Environment: sulfa drugs containing five-membered heterocyclic groups. Environ. Sci. Technol. 38, 3933-3940.

3. Schroering, Caitlin. (2019) Water is a Human Right Grassroots Resistance to Corporate Power. JOURNAL OF WORLD-SYSTEMS RESEARCH. 25:28-34.

4. ZHANG Ai-Ping, YANG Shi-Qi, YI Jun, et al. (2010) Analysis on current situation of water pollution and pollutant sources in Ningxia Yellow River irrigation region[J]. Chinese Journal of EcoAgriculture, Nov. 18(6): 1295-1301.

5. Tao Baoxian, Zhang Baohua, Dong Jie, et al. (2019) Antagonistic effect of nitrogen additions and warming on litter decomposition in the coastal wetland of the Yellow River Delta, China ECOLOGICAL ENGINEERING, 131:1-8.

6. YU Tao, CHEN Jing-shen. (2004) Impacts of the Agricultural Development on the Water Quality and Nitrogen Pollution of the Yellow River-Case of Ningxia Ir rigation Area [J]. Journal of Arid Land Resources and Envi ro nment, 18(5):1-7.

7. Barry, C. D., Foy, R. H. (2016) Assessing the success of regional measures for lowering agricultural nutrient pollution in headwater streams. J. Environ. Qual. 45, 1329-1343.

8. Bowes, M. J., Neal, C., Jarvie, H. P., et al. (2010) Predicting phosphorus concentrations in British rivers resulting from the introduction of improved phosphorus removal from sewage effluent. Sci. Total Environ. 408, 4239-4250. 
9. Simon Harrison, Cassandra McAree, William Mulville, et al. (2019) The problem of agricultural 'diffuse' pollution: Getting to the point. Science of the Total Environment, 677: 700-717.

10. Chen, D. J., Dahlgren, R. A., Lu, J. (2013) A modified load apportionment model for identifying point and diffuse source nutrient inputs to rivers from stream monitoring data. J. Hydrol. 501, 25-34.

11. Curtis, C. J., Evans, C. D., Goodale, C. L., et al. (2011) What have stable isotope studies revealed about the nature and mechanisms of $\mathrm{N}$ saturation and nitrate leaching from semi-natural catchments. Ecosystems 14, 1021-1037.

12. Davison, P. S., Withers, P. J. A., Lord, E. I., et al. (2008) PSYCHIC - a process-based model of phosphorus and sediment transfers within agricultural catchments. Part 1.Model description and parameterisation. J. Hydrol. 350, 290-302

13. Doody, D. G., Augustenborg, C. A., Withers, P. J. A., et al. (2015) A systematic map protocol: what evidence exists to link agricultural practices with ecological impacts for Irish waterbodies? Environ. Evid. 4, 14.

14. YANG Lihui, WANG Shaoli, RUAN Benqing, et al. (2015) Evolution of drain-based research of irrigation return flow pollution in Yinbei Irrigation Area.Chinese Journal of Eco-Agriculture, 23(12): 1580-1587

15. Liu G Q, Yang S Q. (2010) Analysis on present situation of subsiding water from cropland in Ningxia irrigation area from the Huanghe River. Journal of Irrigation and Drainage, 29(1): 104-108.

16. Strock J S, Dell C J, Schmidt J P. (2007) Managing natural processes in drainage ditches for nonpoint source nitrogen control.Journal of Soil and Water Conservation, 62(4):188-197.

17. Zhao Y, Pei Y S, Lu C Y. (2009) Comparison of effective utilization coefficient of irrigated water in large irrigation districts. China Water Resources, 3: 14-17.

18. Yang S J, Zhang A P, Yang Z L, et al. (2009) Agricultural non-point source pollution in Ningxia Irrigation District and preliminary study of load estimation methods. Scientia Agricultura Sinica, 42(11): 3947-3955.

19. Yan L, Huang J H, Zhang J J, et al. (2007) Impacts of farmland drainage from Ningxia on quality of Yellow River. Yellow River, 29(3): 35-36.

20. Li Q K, Hu Y W, Luo L G. (2012) Source characteristics analysis of discharge and pollutants in typical drainage ditch of Qingtongxia Irrigation District. Environmental Science, 33(5): 1579-1586.

21. Yang S J, Zhang A P, Yang S Q, et al. (2009) Investigation of agricultural non-point source pollution in Ningxia irrigation district and analysis of its factors. Agricultural Research in the Arid Areas, 27(5): 256-260.
22. WANG S L, XU D, YANG J G, etal. (2011) Chemical characteristics and its irrigation effect of drainage water in ditches of Yinbei Irrigation Districts . SHUILI XUEBAO, 42(2):166-172.

23. TIAN L F, HU J W, QIN F X, et al. (2011) Statistical analysis of distribution characteristics of heavy metals in surface water from Baihua Lake . Research of Environmental Sciences, 24(3): 16-24 .

24. TIAN L F, HU J W, QIN F X, et al. (2011) Distribation of heavy metal elements in the water body from Lake Hongfeng . China Environmental Science, 31(3): 481-489.

25. TIAN L F, HU J W, QIN F X, et al. (2011) Geochemical characteristics and risk assessment of heavy metals in sediments from Lake Hongfeng . Environmental Chemistry, 30(9): 1590-1597.

26. TIAN L F, HU J W, HUANG X F, et al. (2011) Ecological risk and stability of heavy metals in sediments from Lake Baihua in Guizhou Province. Acta Scientiae Circumstantiae, 32(4): 885-894.

27. NI Q S, LIU X D. (2007) SPSS Application Test Tutorial. Henan: Henan University Press.

28. XIAO J, HANG Y, CHEN Y L, et al. (2013) Assessment of Yellow River basin in water quality of state-controlled sections in based on principal component analysis method. Water Saving Irrigation, 22(10): 31-34.

29. LI X S, CHENG Z Z. (2010) Correctly using SPSS software for principal components analysis. Statistical Research, 27(4):105-108. 